\title{
ANALISIS PENGARUH PANJANG SUDU TERHADAP UNJUK KERJA TURBIN ANGIN ATAP RUMAH PADA KECEPATAN ANGIN RENDAH
}

\author{
${ }^{(1)}$ Mujiburrahman, ${ }^{(2)}$ Heri Irawan \\ ${ }^{(1)(2)}$ Teknik Mesin, Fakultas Teknik, Universitas Islam Kalimantan MAB \\ Jl. Adhiyaksa No. 2 Kayu Tangi, Banjarmasin \\ Email :_Mujiburrahman.4646@gmail.com,Heri.irawan.up@gmail.com
}

\begin{abstract}
Abstrak
Mengingat potensi angin di Banjarmasin tergolong rendah, hasil pengukuran kecepatan angin secara langsung menggunakan anemometer dengan durasi rata - rata perjam yang ada di puncak kemiringan atap berkisar antara $2 \mathrm{~m} / \mathrm{s}$ sampai $6 \mathrm{~m} / \mathrm{s}$. Dengan demikian di butuhkan sebuah sistem konversi angin yang yang optimal pada kecepatan angin rendah di kemiringan atap. Atas dasar pertimbangan peneliti sebelumnya maka turbin atap rumah dalam penelitian ini menggunakan Airfoil savonius karena memiliki self-starting torsi yang baik untuk kecepatan angin yang rendah sehingga memiliki performansi yang baik apabila di aplikasikan pada turbin angin atap rumah. Mungkin yang menjadi pertanyaan adalah seberapa efektif turbin angin yang di aplikasikan pada atap rumah, untuk itu pentingnya sebuah eksprimen pengujian dengan membuat model uji turbin atap rumah yang di simulasikan pada wind tunnel untuk mendapatkan parameter desain optimal sebagai rekomendasi mengembangan turbin atap rumah skala besar. Penelitian ini menggunakan metode penelitian eksperimental (experimental research) yaitu melakukan pengamatan dan pengukuran kecepatan angin di kemiringan atap dengan durasi rata-rata perjam, perhari, dan perbulan menggunakan alat ukur anemometer digital. Selanjutnya data tersebut dijadikan sebagai parameter awal dalam menentukan variasi kecepatan angin dalam pengujian model eksprimen pada terowongan angin sederhana dengan varibel kecepatan angin kemiringan atap dan panjang turbin terhadap unjuk kerja turbin atap rumah hasil pengujian. Hasil pengujian pada kecepatan angin 2 $\mathrm{m} / \mathrm{s}$ turbin atap rumah yang memberikan pengaruh paling besar di hasilkan oleh panjang $0,25 \mathrm{~m}$, dengan nilai putaran sebesar $257,1 \mathrm{rpm}$. Hasil pengujian pada kecepatan angin 3 $\mathrm{m} / \mathrm{s}$ turbin atap rumah yang memberikan pengaruh paling besar di hasilkan oleh panjang $0,30 \mathrm{~m}$, dengan nilai putaran sebesar 202,4 rpm. Hasil pengujian pada kecepatan angin 5 $\mathrm{m} / \mathrm{s}$ turbin atap rumah yang memberikan pengaruh paling besar di hasilkan oleh panjang 0,25 $\mathrm{m}$, dengan nilai putaran sebesar 295,6 rpm.
\end{abstract}

Kata kunci: Turbin atap rumah, Airfoil savonius, Putaran rendah

\begin{abstract}
Considering the wind potential in Banjarmasin is relatively low, the results of direct measurement of wind speed using anemometer with the average duration of the hour at the top of the roof slope range from $2 \mathrm{~m} / \mathrm{s}$ to $6 \mathrm{~m} / \mathrm{s}$. Thus an optimal wind conversion system is needed at low wind speeds on the slope of the roof. On the basis of previous researchers' considerations, the house roof turbine in this study used Airfoil savonius because it has good self-starting torque for low wind speeds so that it has good
\end{abstract}


performance when applied to a house roof wind turbine. Perhaps the question is how effective the wind turbine is applied to the roof of the house, for that the importance of a testing experiment by making a home roof turbine test model simulated in the wind tunnel to obtain optimal design parameters as a recommendation to develop a largescale home roof turbine. This study uses experimental research methods, namely observing and measuring wind speed on the slope of the roof with an average duration of hourly, daily, and monthly using a digital anemometer. Furthermore, the data is used as an initial parameter in determining wind speed variations in testing experimental models in simple wind tunnels with variable roof slope wind speeds and turbine lengths against the performance of the roof turbine test results. The test results on wind speeds of $2 \mathrm{~m} / \mathrm{s}$ house roof turbines that provide the most influence are generated by a length of $0.25 \mathrm{~m}$, with a rotation value of $257.1 \mathrm{rpm}$. The test results on the wind speed of $3 \mathrm{~m} /$ $s$ house roof turbines that provide the most influence are produced by a length of 0.30 $m$, with a rotation value of 202.4 rpm. The test results on the wind speed of $5 \mathrm{~m} / \mathrm{s}$ house roof turbines that provide the most influence are generated by a length of $0.25 \mathrm{~m}$, with a rotation value of $295.6 \mathrm{rpm}$.

Keywords: Roof top turbine, Airfoil savonius, Low Round

\section{PENDAHULUAN}

Beberapa kajian turbin atap rumah pernah dilakukan dimana turbin angin yang ditempatkan di atap rumah dengan struktur menara yang di anggap tidak efektif dari segi efesiensi dan biaya, salah satunya sistem bargey, Popular Mechanics ,2009. Raymond E. Paggi, 2010. Meneliti turbin atap rumah dengan sudu datar yang di aplikasikan pada bangunan yang memiliki atap miring. dengan menempatkan turbin angin desain memanjang tanpa struktur tiang, pada bangunan atap miring. Lucas Daesadze, dkk, 2013. Meneliti turbin atap rumah tipe savonius tipe $\mathrm{U}$ dengan struktur tiang untuk potensi angin rendah. Selanjutnya Eka Maulana, dkk, 2016. Meneliti turbin atap rumah dengan konsep memanjang menggunakan airfoil savonius tipe L, untuk potensi angin rendah. Hal yang sama di lakukan Mujiburrahman, Heri Irawan 2018. Menelitian yang sama tentang potensi turbin angin atap rumah bentuk memanjang menggunakan airfoil savonius tipe U dengan simulasi CFD.

Mengingat potensi angin di Banjarmasin tergolong rendah, hasil pengukuran kecepatan angin secara langsung menggunakan anemometer dengan durasi rata - rata perjam yang ada di puncak kemiringan atap berkisar antara $2 \mathrm{~m} / \mathrm{s}$ sampai $6 \mathrm{~m} / \mathrm{s}$. Dengan demikian di butuhkan sebuah sistem konversi angin yang yang optimal pada kecepatan angin rendah di kemiringan atap.

Atas dasar pertimbangan peneliti sebelumnya maka turbin atap rumah dalam penelitian ini menggunakan Airfoil savonius karena memiliki selfstarting torsi yang baik untuk kecepatan angin yang rendah sehingga memiliki performansi yang baik apabila di aplikasikan pada turbin angin atap rumah.

Selain itu juga karena bentuk turbin memanjang di anggap efektif memaksimalkan sapuan angin di puncak kemiringan atap. Dengan demikian permasalahan dalam penelitian ini di fokuskan pada kecepatan angin di kemiringan atap yang rendah dan berpluktuatif, selanjutnya panjang turbin juga memiliki pengaruh yang besar dalam menghasilkan tangkapan angin, sehingga dengan dukungan bentuk Aerodinamis Airfoil Savonius tipe $L$ turbin angin atap rumah dirasa mampu berputar dengan optimal pada kecepatan angin rendah. 
p-ISSN 2502-4922,e-ISSN 2615-0867

Mungkin yang menjadi pertanyaan adalah seberapa efektif turbin angin yang di aplikasikan pada atap rumah, untuk itu pentingnya sebuah eksprimen pengujian dengan membuat model uji turbin atap rumah yang di simulasikan pada wind tunnel untuk mendapatkan parameter desain optimal sebagai rekomendasi mengembangan turbin atap rumah skala besar.

\section{METODE PENELITIAN Diagram Alir Penelitian}

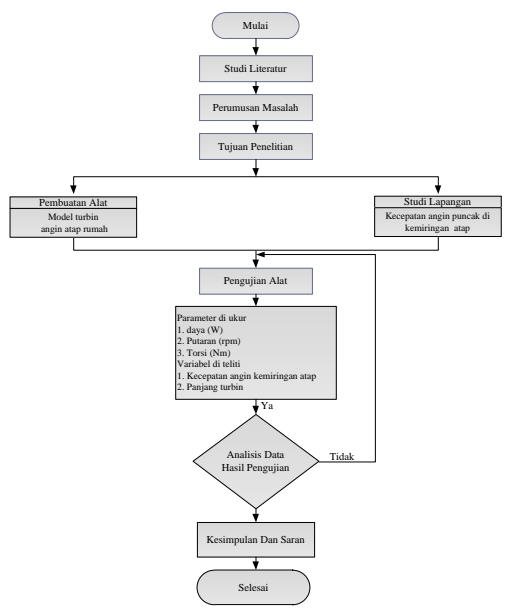

Gambar 3.1. Flow chart penelitian

\section{Tempat dan Waktu Penelitian}

Penelitian ini rencanakan selama 6 bulan, terhitung dari bulan oktober 2018 sampai dengan bulan maret 2019. Pengukuran data angin dilakukan di puncak kemiringan atap rumah daerah banjarmasin. Sedangkan pengujian model turbin dilakukan di laboraturium fakultas teknik menggunakan terowongan angin. Objek penelitian di fokuskan pada bagian panjang turbin menggunakan airfoil savonius tipe L sudu 3, terhadap unjuk kerja turbin angin atap rumah.

Tabel 3.1 Spesifikasi Turbin Atap

Rumah

\begin{tabular}{|c|c|c|c|}
\hline \multirow[t]{2}{*}{ No } & \multicolumn{3}{|c|}{$\begin{array}{cl}\text { Spesifikasi Turbin Angin Atap } \\
\text { Rumah }\end{array}$} \\
\hline & Tipe & Ukuran & Satuan \\
\hline 1 & $\begin{array}{l}\text { Diameter } \\
\text { Rotor }\end{array}$ & 0,10 & $\mathrm{~m}$ \\
\hline 2 & Panjang & $0,15,0,25$ & $\mathrm{~m}$ \\
\hline
\end{tabular}

\begin{tabular}{|c|l|l|l|} 
& $\begin{array}{l}\text { Sudu } \\
\text { Turbin }\end{array}$ & dan 0,30 & \\
\hline 3 & $\begin{array}{l}\text { Jumlah } \\
\text { Sudu }\end{array}$ & 3 & buah \\
\hline 4 & $\begin{array}{l}\text { Lengkung } \\
\text { Ujung Sudu }\end{array}$ & 10 & derajad \\
\hline 5 & $\begin{array}{l}\text { Diameter } \\
\text { Poros }\end{array}$ & 12 & $\mathrm{~mm}$ \\
\hline 6 & Tebal Sudu & 1,5 & $\mathrm{~mm}$ \\
\hline 7 & $\begin{array}{l}\text { Airfoil } \\
\text { Sudu }\end{array}$ & $\begin{array}{l}\text { Savonius } \\
\text { tipe L }\end{array}$ & - \\
\hline 8 & $\begin{array}{l}\text { Material } \\
\text { Sudu }\end{array}$ & Aluminium & - \\
\hline 9 & $\begin{array}{l}\text { Kemiringan } \\
\text { Atap }\end{array}$ & 35 & Derajad \\
\hline
\end{tabular}

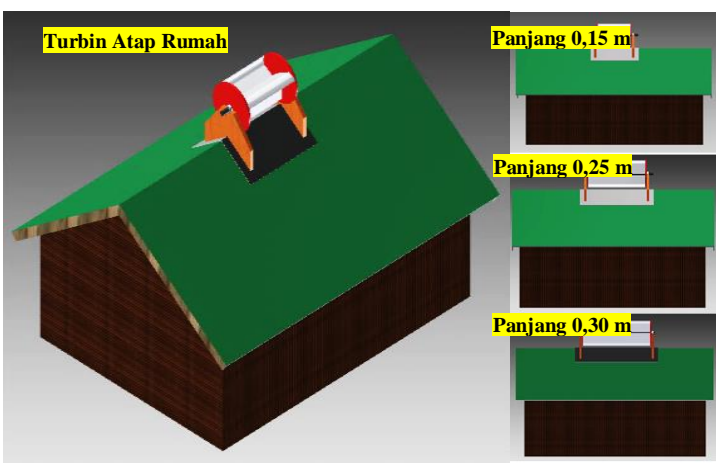

Gambar 3.2. Desain turbin atap rumah

\section{Metode Penelitian}

Penelitian ini dilakukan dengan menggunakan metode penelitian eksperimental (experimental research) yaitu melakukan pengamatan dan pengukuran kecepatan angin di kemiringan atap dengan durasi rata-rata perjam, perhari, dan perbulan menggunakan alat ukur anemometer digital. Selanjutnya data tersebut dijadikan sebagai parameter awal dalam menentukan variasi kecepatan angin dalam pengujian model eksprimen pada terowongan angin sederhana dengan varibel kecepatan angin kemiringan atap dan panjang turbin terhadap unjuk kerja turbin atap rumah hasil pengujian.

\section{Bahan dan Alat}

Bahan dan alat yang digunakan untuk pembuatan turbin angin atap rumah sebagai berikut : 


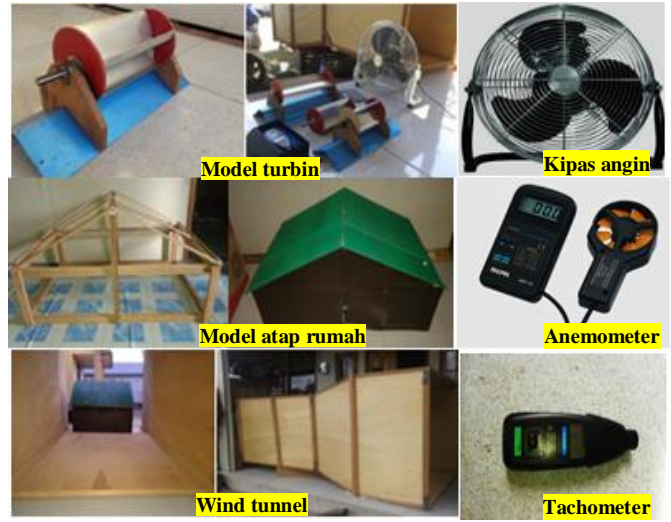

Gambar 3.3. Alat dan bahan

\section{Langkah - Langkah Pengujian}

Pegujian di lakukan dengan tahapan sebagai berikut :

1. Site up peralatan pengujian

2. Mengukur keseragan aliran seksi uji

3. Site up kecepatan angin

4. Menyiapkan model uji

5. Pengujian

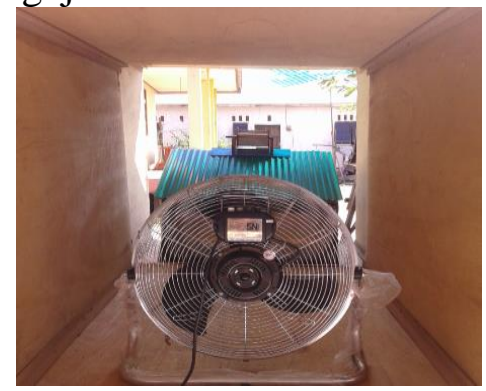

Gambar 3.4. Skema pengujian turbin

\section{HASIL DAN PEMBAHASAN}

Sebagai langkah awal penelitian ialah data potensi angin hasil pengukuran di kemiringan atap selama 2 bulan, dengan durasi waktu pengukuran rata - rata per jam, harian dan bulanan, langkah selanjutnya kecepatan angin tersebut di jadikan variabel dalam akuisisi data pengujian di simulasikan pada wind tunnel yaitu 2, 3, dan $5 \mathrm{~m} / \mathrm{s}$ dengan menitikberatkan masalah pada pengaruh panjang turbin yaitu $0,15,0,25$, dan $0,30 \mathrm{~m}$ yang memberikan pengaruh paling besar terhadap unjuk kerja turbin atap rumah. Dengan langkah - langkah perhitungan dan pengujian sebagai berikut.

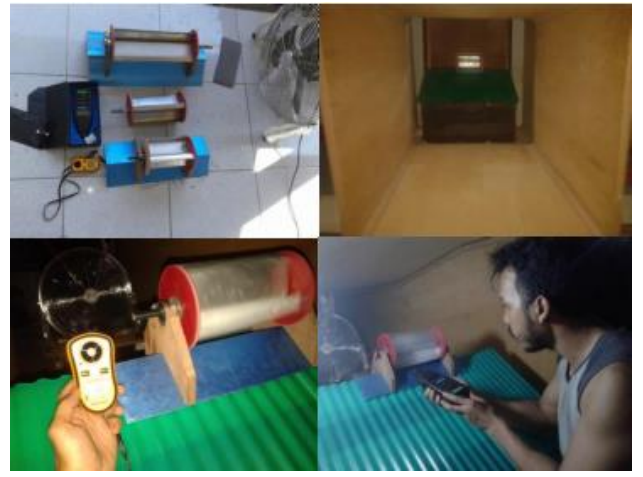

Gambar 4.1. Pengujian Turbin Atap

Rumah

1. Contoh menghitung Luas penampang turbin atap rumah panjang $0,15 \mathrm{~m}$ menggunakan persamaan berikut :

$\mathrm{A}=\mathrm{d} \times \mathrm{h}$

$\mathrm{A}=0,10 \times 0,15$

$\mathrm{A}=0,015 \mathrm{~m}$

Tabel. 4.1. Hasil Perhitungan Luas Penampang Turbin Angin Atap Rumah

\begin{tabular}{|c|c|c|c|}
\hline No & $\begin{array}{c}\text { Diameter } \\
\text { Turbin, } d \\
(\mathrm{~m})\end{array}$ & $\begin{array}{c}\text { Panjang } \\
\text { Turbin, } \mathrm{h} \\
(\mathrm{m})\end{array}$ & $\begin{array}{c}\text { Luas } \\
\text { penampang } \\
\mathrm{A}\left(\mathrm{m}^{2}\right)\end{array}$ \\
\hline 1 & $0,10 \mathrm{~m}$ & $0,15 \mathrm{~m}$ & 0,015 \\
\hline 2 & $0,10 \mathrm{~m}$ & $0,25 \mathrm{~m}$ & 0,025 \\
\hline 3 & $0,10 \mathrm{~m}$ & $0,30 \mathrm{~m}$ & 0,030 \\
\hline
\end{tabular}

2. Contoh menghitung daya potensial yang di hasilkan panjang turbin 0,15 $\mathrm{m}$, pada kecepatan angin $2 \mathrm{~m} / \mathrm{s}$.

$$
\begin{aligned}
& \mathrm{P}=\frac{1}{2} \cdot \mathrm{Cp} \cdot \rho \cdot \mathrm{A}^{2} \cdot \pi \cdot \mathrm{v}^{3} \\
& \mathrm{P}=\frac{1}{2} \times 0,59 \times 1,225 \times 0,015 \times 3,14 \times 2^{3} \\
& \mathrm{P}=0,136 \mathrm{~W}
\end{aligned}
$$

Tabel. 4.2. Hasil Perhitungan Daya Potensial Turbin Angin Atap Rumah

\begin{tabular}{|c|c|c|c|}
\hline No & $\begin{array}{c}\text { Kecepatan } \\
\text { angin, v } \\
(\mathrm{m} / \mathrm{s})\end{array}$ & $\begin{array}{c}\text { Luas } \\
\text { penampang, } \\
\text { A }\left(\mathrm{m}^{2}\right)\end{array}$ & $\begin{array}{c}\text { Daya } \\
\text { Potensial, } \\
\text { P }(\mathrm{W})\end{array}$ \\
\hline 1 & $2 \mathrm{~m} / \mathrm{s}$ & $0,015 \mathrm{~m}$ & 0,136 \\
\hline 2 & $2 \mathrm{~m} / \mathrm{s}$ & $0,025 \mathrm{~m}$ & 0,227 \\
\hline 3 & $2 \mathrm{~m} / \mathrm{s}$ & $0,030 \mathrm{~m}$ & 0,272 \\
\hline 4 & $3 \mathrm{~m} / \mathrm{s}$ & $0,015 \mathrm{~m}$ & 0,459 \\
\hline 5 & $3 \mathrm{~m} / \mathrm{s}$ & $0,025 \mathrm{~m}$ & 0,766 \\
\hline 6 & $3 \mathrm{~m} / \mathrm{s}$ & $0,030 \mathrm{~m}$ & 0,919 \\
\hline 7 & $5 \mathrm{~m} / \mathrm{s}$ & $0,015 \mathrm{~m}$ & 2,128 \\
\hline
\end{tabular}




\begin{tabular}{|l|l|l|l|}
\hline 8 & $5 \mathrm{~m} / \mathrm{s}$ & $0,025 \mathrm{~m}$ & 3,546 \\
\hline 9 & $5 \mathrm{~m} / \mathrm{s}$ & $0,030 \mathrm{~m}$ & 4,255 \\
\hline
\end{tabular}

3. Hasil pengujian putaran poros turbin angin atap rumah

Tabel. 4.3. Hasil Pengujian Putaran Turbin

Angin Atap Rumah

\begin{tabular}{|c|c|c|c|}
\hline No & $\begin{array}{c}\text { Kecepatan } \\
\text { angin, } \\
(\mathrm{m} / \mathrm{s})\end{array}$ & $\begin{array}{c}\text { Panjang } \\
\text { Turbin } \\
(\mathrm{m})\end{array}$ & $\begin{array}{c}\text { Putaran, } \\
\text { N (rpm) }\end{array}$ \\
\hline 1 & $2 \mathrm{~m} / \mathrm{s}$ & $0,15 \mathrm{~m}$ & 157,4 \\
\hline 2 & $2 \mathrm{~m} / \mathrm{s}$ & $0,25 \mathrm{~m}$ & 257,1 \\
\hline 3 & $2 \mathrm{~m} / \mathrm{s}$ & $0,30 \mathrm{~m}$ & 160,4 \\
\hline 4 & $3 \mathrm{~m} / \mathrm{s}$ & $0,25 \mathrm{~m}$ & 182,3 \\
\hline 5 & $3 \mathrm{~m} / \mathrm{s}$ & $0,30 \mathrm{~m}$ & 198,5 \\
\hline 6 & $3 \mathrm{~m} / \mathrm{s}$ & $0,15 \mathrm{~m}$ & 202,4 \\
\hline 7 & $5 \mathrm{~m} / \mathrm{s}$ & $0,30 \mathrm{~m}$ & 280,6 \\
\hline 8 & $5 \mathrm{~m} / \mathrm{s}$ & $0,15 \mathrm{~m}$ & 295,6 \\
\hline 9 & $5 \mathrm{~m} / \mathrm{s}$ & $0,25 \mathrm{~m}$ & 228,3 \\
\hline
\end{tabular}

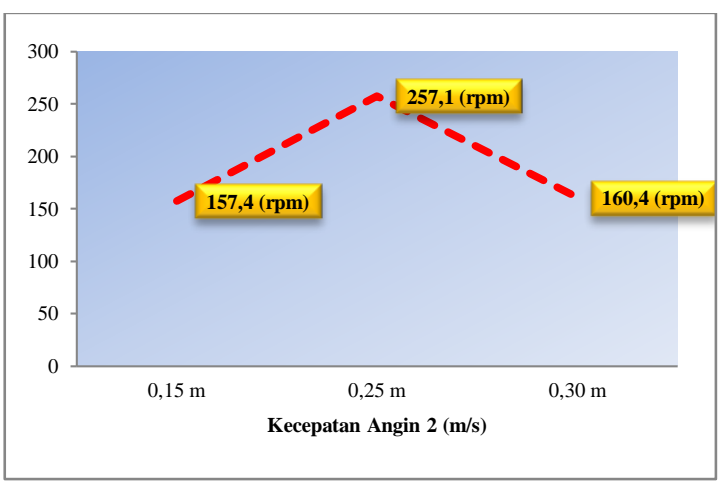

Gambar Grafik 4.1. Pengaruh Panjang Turbin Terhadap Putaran Pada Kecepatan Angin 2 m/s

Hasil pengujian pada gambar grafik 4.1. Menunjukkan bahwa pada kecepatan angin $2 \mathrm{~m} / \mathrm{s}$ turbin atap rumah yang memberikan pengaruh paling besar di tunjukkan oleh panjang $0,25 \mathrm{~m}$, dengan nilai putaran sebesar 257,1 rpm, selanjutnya pada kecepatan angin yang sama turbin atap rumah dengan panjang $0,30 \mathrm{~m}$, menghasilkan nilai putaran lebih rendah sebesar 160,4 rpm, dan sedangkan turbin atap rumah dengan panjang $0,15 \mathrm{~m}$, hanya mampu menghasilkan nilai putaran sebesar $157,4 \mathrm{rpm}$.

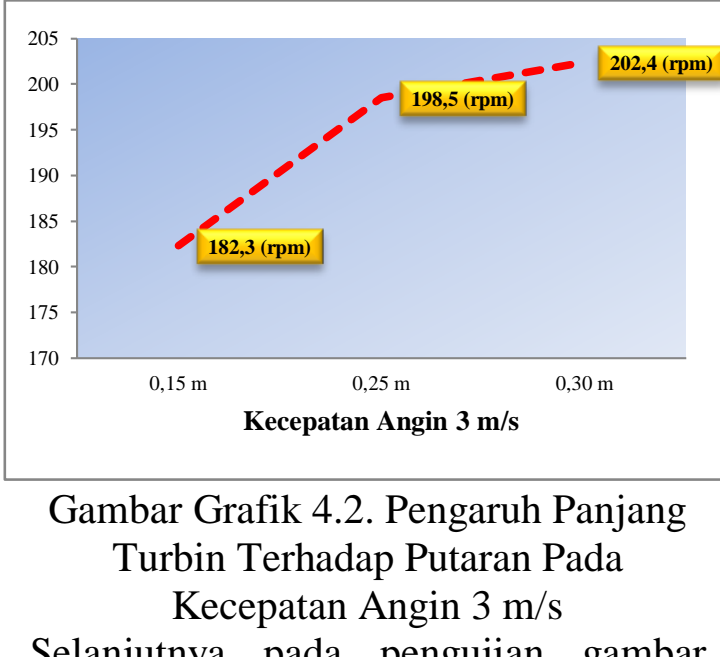

Selanjutnya pada pengujian gambar grafik 4.2. Menunjukkan hasil yang berbeda dari sebelumnya dimana pada kecepatan angin $3 \mathrm{~m} / \mathrm{s}$ turbin atap rumah yang memberikan pengaruh paling besar justru di tunjukkan oleh panjang $0,30 \mathrm{~m}$, dengan nilai putaran sebesar 202,4 rpm, selanjutnya pada kecepatan angin yang sama turbin atap rumah dengan panjang $0,25 \mathrm{~m}$, menghasilkan nilai putaran lebih rendah sebesar 198,5 rpm, dan sedangkan turbin atap rumah dengan panjang 0,15 $m$ tetap berada pada hasil yang paling rendah, hanya mampu menghasilkan nilai putaran sebesar $182,3 \mathrm{rpm}$.

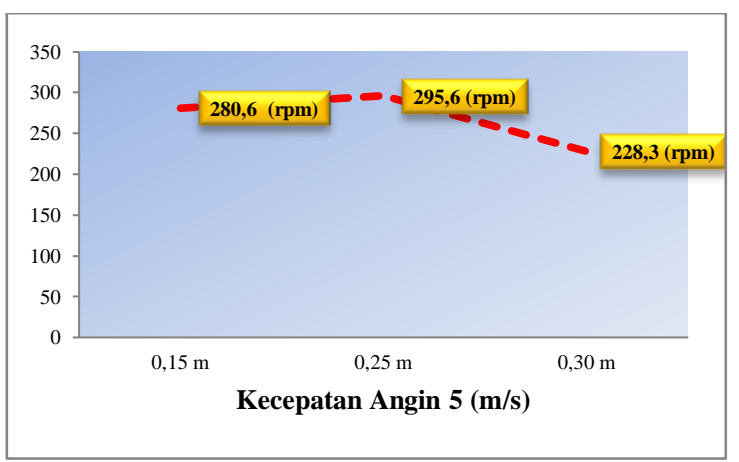

Gambar Grafik 4.3. Pengaruh Panjang Turbin Terhadap Putaran Pada Kecepatan Angin $5 \mathrm{~m} / \mathrm{s}$

Sedangkan pada hasil pengujian gambar grafik 4.3. Menunjukkan capaian hasil yang berbeda dari sebelumnya dimana pada kecepatan angin $5 \mathrm{~m} / \mathrm{s}$ turbin atap rumah dengan panjang $0,25 \mathrm{~m}$, secara keseluruhan kembali menunjukkan unjuk kerja yang paling maksimum dengan nilai putaran sebesar 295,6 rpm, 
selanjutnya pada kecepatan angin yang sama yaitu $5 \mathrm{~m} / \mathrm{s}$ turbin atap rumah dengan panjang $0,15 \mathrm{~m}$, mampu menunjukkan kinerja putaran lebih baik dari sebelumnya nilai putaran yang di hasilkan sebesar 280,6 rpm, sedangkan turbin atap rumah dengan panjang 0,30 pada kecepatan angin $5 \mathrm{~m} / \mathrm{s}$ justru mengalami peningkatan yang kurang signifikan hanya mampu menghasilkan nilai putaran sebesar 228,3 rpm, memiliki kinerja lebih rendah dari turbin atap rumah panjang $0,25 \mathrm{~m}$, dan $0,15 \mathrm{~m}$.

\section{KESIMPULAN}

1. Hasil pengujian pada kecepatan angin $2 \mathrm{~m} / \mathrm{s}$ turbin atap rumah yang memberikan pengaruh paling besar di hasilkan oleh panjang $0,25 \mathrm{~m}$, dengan nilai putaran sebesar 257,1 rpm.

2. Hasil pengujian pada kecepatan angin $3 \mathrm{~m} / \mathrm{s}$ turbin atap rumah yang memberikan pengaruh paling besar di hasilkan oleh panjang $0,30 \mathrm{~m}$, dengan nilai putaran sebesar 202,4 rpm.

3. Hasil pengujian pada kecepatan angin $5 \mathrm{~m} / \mathrm{s}$ turbin atap rumah yang memberikan pengaruh paling besar di hasilkan oleh panjang $0,25 \mathrm{~m}$, dengan nilai putaran sebesar 295,6 rpm..

\section{REFERENSI}

[1] Mujiburrahman, Heri Irawan 2018. Analisis Pengaruh Sudu Terhadap Unjuk Kerja Turbin Angin Atap Rumah Pada Kecepatan Angin Rendah Menggunakan Simulasi Cfd.

[2] Eka Maulana, Mujiburrahman, Iskendar, 2016. Meneliti Pengaruh Sudu Terhadap Unjuk Kerja Turbin Angin Atap Rumah Pada Putaran Rendah.

[3] Lukas deisadze, dkk 2013. Vertical Axis Wind Turbine Evaluation and Design.
[4] Andry kusbiantoro, dkk 2013. Pengaruh Lengkung Sudu Terhadap Unjuk Kerja Turbin Angin Poros Vertikal Savonius.

[5] Hendra A. 2012, Pengaruh Jumlah Sudu Terhadap Unjuk KerjaTurbin Angin Savonius.Universitas Brawijaya.

[6] Raymond E. Paggi, 2010. Paten Application Ser. No. 61/105,096, filed Nov.24, 2008, Entidled Roof Ridge Wind Turbine.

[7] Andreas Andi Setiawan, dkk 2010. Pengaruh Jarak Celah Sudu Terhadap Unjuk Kerja Turbin Angin Poros Vertikal Savonius.

[8] Tong, W. 2010. Wind Power Generation and Wind Turbine Design. USA: WIT Press.

[9] Lubitz. 2008. Effec Roof Slope on a Building Monted Wind Turbine.

[10] Watson et, 2008, Estimating The Potential Yield of Small Building - Monted Wind Turbines.

[11] Sargolzaei, J. 2007. Prediction of the power ratio and torque in wind turbine Savonius rotors using artificial neural networks. Department of chemical engineering. Ferdowsi university of Mashhad. Iran.

[12] W. D. Lubitz, B. R. White, 2004. Atmospheric Boundary Layer Wind Tunnel Applicationsin Wind Turbine Siting. 